NASA/TM- $-97-\quad 207869$

210

In. $76-7 n$

Reprinted from

$C$

$10.8 \times$

JOURNAL OF

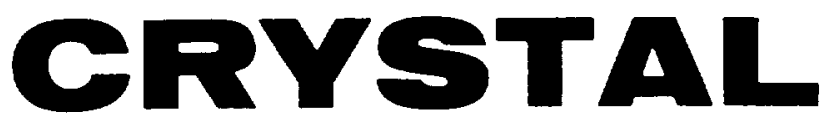

GROWTH

Characterization of cadmium-zinc telluride crystals grown by 'contactless' PVT using synchrotron white beam topography

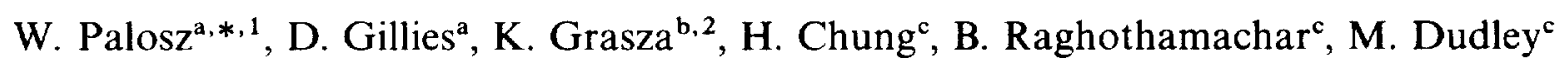

${ }^{2}$ NASA-MSFC, Huntsville, AL 35812, USA

'IPPAS, Warsaw, Poland

'SUNY at Stony Brook, NY 11794, USA

Received 2 February 1997; accepted 2 May 1997

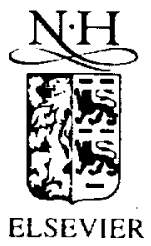




\section{Journal of Crystal Growth}

\section{EDITORIAL BOARD}

M SCHIEBER (Principal Editor)

The Fredy and Nadine Herrmann Graduate School of Appl. Sci.

Hebrew University, Jerusalem 91904, Israel

Telelax: + 972-2-566 3878

R. KERN

CRMC ${ }^{2}$. CNRS, Campus Luminy, Case 913

F-13288 Marseille Cedex 9, France

Telefax: + 33-91-4-418916

\author{
R.S. FEIGELSON \\ Ctr. Materials Res., $105 \mathrm{McCullough} \mathrm{Bldg.}$ \\ Stanford Univ., Stanford, CA 94305-4045, USA \\ Telefax: + 1-415-7233044 \\ T. NISHINAGA \\ Dept. Electron. Eng., Univ. of Tokyo \\ 7-3-1, Hongo, Bunkyo-ku, Tokyo 113, Japan \\ Telefax: + 81-3-5684-3974
}

\section{ASSOCIATE EDITORS}

A. BARONNET (Industrial, Biological, Molecular Crystals) CRMC $^{2}$, CNRS, Campus Luminy. Case 913

F-13288 Marseille Cedex 9, France

Telefax: + 33-91-4-418916

K.W. BENZ (Microgravity, Electronic Materials)

Kristallographisches Inst., Universitäl

Hebelstr. 25, D-79104 Freiburg, Germany

Telefax: + 49-761-203 4369

A.A. CHERNOV (Kinetics of Crystallization, Protein Crystallization)

Inst. Crystallography, Acad of Science

Leninskii Prosp., Moscow 117333, Russian Fed.

Telefax: + 7-095-135011

A.Y. CHO (Molecular Beam Epiraxy)

Room IC-323, AT\&T Bell Laboratories

Murray Hill, NJ 07974-2070, USA

Telefax: + 1-908-582 2043

B. COCKAYNE (IOCG News)

School of Metallurgy and Mater.

Univ. Birmingham, P.O. Box 363 ,

Edgbaston, Birmingham, B15 2TT, UK

Telefax: + 44121-4712207

S.R. CORIELL (Theory)

A153 Mater, Natl. Inst. of Standards \& Technol.

Gaithersburgh, MD 20899-0001, USA

Telefax: + 1-30t-975-4553

1.J. DER BY (Computational models)

Depi. Chem. Eng. \& Mater. Sei., Univ. Minnesota

151 Amundson Hall, 421 Washington Ave. S.E.

Minneapolis, MN 55455-0132, USA

Telefax: $+1.612-6267246$

M.E. GLICKSMAN (Solidification)

School of Eng., Mater. Eng. Dept.

Rensselaer Polytechnic Inst.

Troy, NY 12180-3590 USA

Telefax: + I-518-276 B554

M.A.G. HALLIWELL ( $X$-ray Diffraction)

Philips Analytical $X$-ray, Lelyweg 1

7602 EA Almelo. The Netherlands
T. HIBIYA (Oxides, Meit Thermophysical Properties, Microgravity)

Fundamental Res. Labs., NEC COR PORATION

34. Miyukigaoka, Tsukuba 305. Japan

Telefax: + 81-298-566 136

H. KOMATSU (Proteins Molecular Crystallization,

Growth from Solutions)

Inst. Mater. Res., Tohoku Univ.

Katahira 2-1-1, Sendai 980, Japan

Telefax: + 81+22-2152011

T.F. KUECH (Thin Films and Electronic

and Optical Devices)

Dept. Chem. Eng., Univ. Wisconsin-Madison

Madison, WI 53706, USA

Telefax: + 1-608-265 3782

A. McPHERSON (Protein Growth)

Dept. Biochemistry, Univ. of California

Riverside, CA 92521, USA

Telefax: + 1-909.787 3790

P.A. MORRIS HOTSENPILLER (Electrooptical

Crystals, Book Reviews, Oxide Thin Films)

E.1. du Pont de Nemours \& Co. Exp. Station

Wilmington, DE 19888-0358, USA

Telefax: + 1-302-695 1664

J.B. MULLIN (Semiconductors)

EMC, "The Hoo", Brockhill Road

West Malvem, Worcs., WR14 4DL, UK

Telefax: + 44-1684-575591

K. NAKAJIMA (Liquid and Vapor Phase Epiraxy) Integrated Mater. Lab., Fujitsu Labs. Ltd.

Morinosato-Wakamiya 10-1, Atsugi 243-01, Japan

Telefax: + 81-462-48 3473

H. OHNO (Epiaxy)

Research Inst. of Electrical Commun

Tohoku Univ., Sendai 98077 , Japan

Telefax: $+81-22-2175553$

K. PLOOG (Molecular Beam Epitaxy)

Paul-Drude-Inst. fur Festkörperelektronik

Hausvogteiplatz 5-7, D-10117 Berlin. Germany

Telefax: + 49-30-203 77201
DT J. HURLE

H.H. Wilts Phys. Lab., Univ. Bristol

Tyndall Avenue

Bristol BS8 1TL, UK

G.B. STRINGFELLOW

Dept. Mater. Sci., 304 EMRO, Univ, of Utah

Salt Lake City, UT 84112, USA

Telefax: + 1-801-581 4816
R.W. ROUSSEAU (Solution Growth,

Industrial Crystalization

School of Chem. Eng., Georgia Inst. of Technol

Atlanta, GA 30332-0100, USA

Telefax: + 1.404-894 2866

K. SATO (Biocrystallization and

Organic Crystals

Fac. Appl. Biol. Sci., Hiroshima Univ.

Higashi-Hiroshima 724, Japa

Telefax: + 81-824-227062

L.F. SCHNEEMEYER (Superconductility,

Oxides, Novel Materials)

Room IA-363, AT\&T Bell Labs.

Murray Hill, NJ 07974-2070, USA

Telefax: + 1-908.582 2521

D.W. SHAW (Semiconductors, Epitaxy, Devices) Texas Instruments Inc., P.O. Box 655936, MS 147 Dallas, TX 75265, USA

Telefax: + 1-214-995 7785

I. SUNAGAWA (Minerals)

3-54-2 Kashiwa-cho, Tachikawa-shi

Tokyo 190, Japan

Telefax: + B1-425-35 3637

G. VAN TENDELOO (Electron Microscop:

Fullerenes, Superconductivity]

University of Antwerp, RUCA

Groenenborgerlaan 171, B-2020 Antwerp-Belgium

Telefax: + 32-3-2180217

A.F. WITT (Semiconductor Crystals)

Dept. of Metall. \& Mater. Sci., Massachuset

Inst. of Technol., Cambridge, MA 02139, US A

Telefax: + 1-617.253 5827

A. ZANGWILL (Theory (Epitaxy)

School of Physics, Georgia Inst. of Technol.

Atlanta, GA 30332. USA

Telefax: + 1-404-894 9958

\section{Seope of the Jouranl}

Experimental and theoretical contributions are invited in the following felds: Theory of nucleation and growth, molecular kinetics and transport phenomena crystallization in viscous media such as polymers and glasses. Crystal growth of metals, minerals, semiconductors, magnetics, inorganic organic and biological substances in bult or as thin films. Apperatus instrumentation and icchniques for crysubstances in bulk or as tion methods. Characterization of single crystals by physical and chemical methods.

\section{Abstracted/nodexed in:}

Aluminium Industry Abstracts; Chemical Abstracts; Current Contents; Physical, Chemical and Earth Sciences; El Compendex Plus; Engineered Materials Abstracts Engineering Index; INSPEC: Metals Abstracts.

\begin{abstract}
Subacription Information 1997
Volumes 170181 of Journal of Crystal Growth (ISSN 0022-0248) are scheduled for publication. (Frequency: semimonthly.) Prices are available from the publishers upon request. Subscriptions are accepted on a prepaid basis only. Issues are sent by SAL (Surface Air Lifted) mail wherever this service is available. Airmail rates are ayailable upon request. Please address all enquiries regarding orders and subscriptions to:

Elsevier Science, B.Y.. Order Fulfilment Department

P.O Box 211, 1000 AE Amsterdam. The Netherlands

Tel: $+31204853642 ; \mathrm{Fax}:+31204853598$

Claims for issues not received should be made within six months of our publication (mailing) date.
\end{abstract}

US mailing notice Journal of Crystal Growth (ISSN 0022-0248) is published semimonthly by Elsevier Science BV Molenwerf 1 PO Box 211,1000 AE Amsterdam The Netherlands. Annual subscription price in the USA is US $\$ 7081$ (valid in North. Central and South America only), including air speed delivery. Periodicals postage paid ar Ja, The NY 11431. US postmasters: Send address changes to Journal of Crystal Growth, Publications Expediting, Inc., 200 Meacham Avenue. Elmont NY 11003 . Airfreight and mailing in the USA by
Publications Expediting.

(C) The paper used in this publication meets the requirements of ANSI/NISO Z39.48-1992 (Permanence of Paper)

PRINTED IN THE NETHERLANDS 


\title{
Characterization of cadmium-zinc telluride crystals grown by 'contactless' PVT using synchrotron white beam topography
}

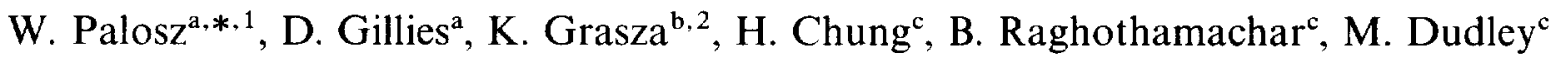 \\ a NASA-MSFC, Huntsille, AL 35812, USA \\ 'IPPAS, Warsaw, Poland \\ 'SUNY at Stony Brook, NY 11794, USA
}

Received 2 February 1997; accepted 2 May 1997

\begin{abstract}
Crystals of $\mathrm{Cd}_{1-x} \mathrm{Zn}_{x}$ Te grown by PVT using self-seeding 'contactless' technique were characterized using synchrotron radiation (reflection, transmission, and Laue back-reflection X-ray topography). Crystals of low ( $x=0.04$ ) and high (up to $x \approx 0.4) \mathrm{ZnTe}$ content were investigated. Twins and defects such as dislocations, precipitates, and slip bands were identified. Extensive inhomogeneous strains present in some samples were found to be generated by interaction (sticking) with the pedestal and by composition gradients in the crystals. Large (up to about $5 \mathrm{~mm}$ ) oval strain fields were observed around some Te precipitates. Low angle grain boundaries were found only in higher $\mathrm{ZnTe}$ content $(x \geqslant 0.2)$ samples.
\end{abstract}

PACS: $81.05 \mathrm{Dz} ; 61.72 . \mathrm{Ff}$

Keywords: PVT; Cadmium-zinc telluride; Defects

\section{Introduction}

High quality crystals of cadmium-zinc telluride are required for fabrication of high performance IR and $\gamma$-ray detectors $[1,2]$. Physical vapor transport (PVT) technique, which allows for a relatively low growth temperature without a presence of a second condensed phase, may offer an improved quality material relative to that grown from the melt. Recently we reported on growth and characterization

${ }^{*}$ Corresponding author.

' Universities Space Research Association.

${ }^{2}$ Currently with Brimrose Corporation. of $\mathrm{Cd}_{1-x} \mathrm{Zn}_{x} \mathrm{Te}$ crystals obtained by seeded and 'contactless' unseeded PVT techniques $[3,4]$. The present work contains additional characterization of the latter performed using synchrotron white beam X-ray topography (SWBXT) in Laue transmission and Bragg reflection geometries [5]. The technique allows both for general characterization as well as imaging of defects in the crystals [5]

\section{Experimental procedure}

Materials and ampoule preparation, and growth of our cadmium-zinc telluride crystals are described 


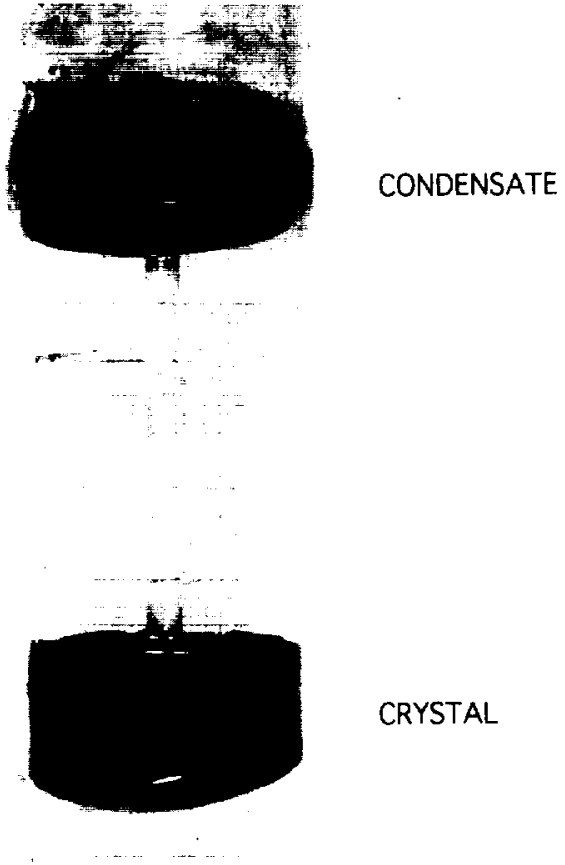

Fig. 1. Crystal in the ampoule after growth (grid in $\mathrm{mm}$ ).
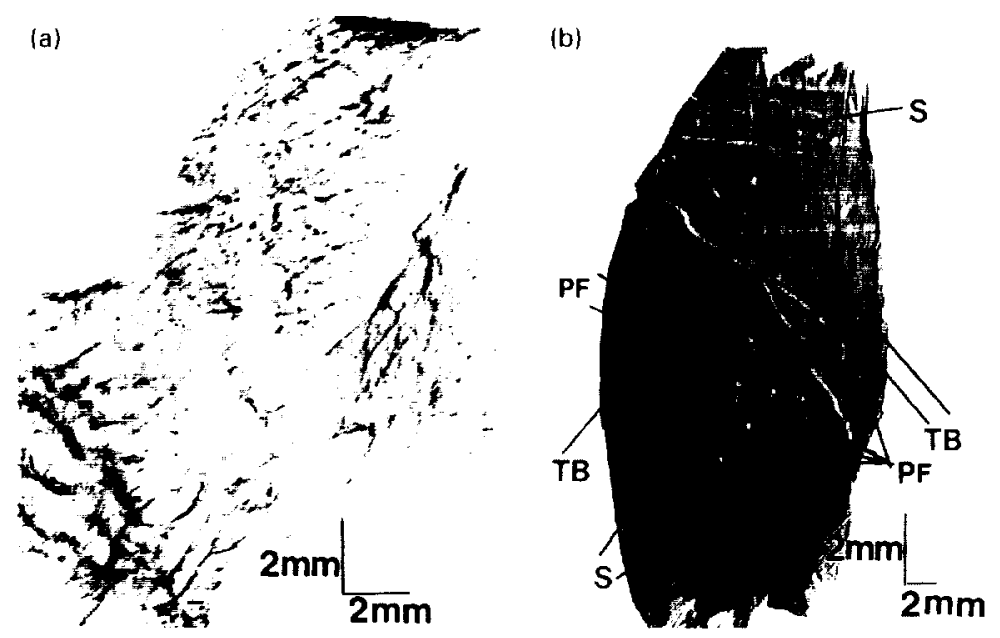

Fig. 2. SWBX reflection topographs of cadmium telluride. PF precipitate contrast features, TB twin boundaries, $\mathrm{S}-\mathrm{slip}$ bands. (a) $z=1 \mathrm{~mm} ;(\mathrm{b}) z=7 \mathrm{~mm}, \boldsymbol{g}=(220)$. 


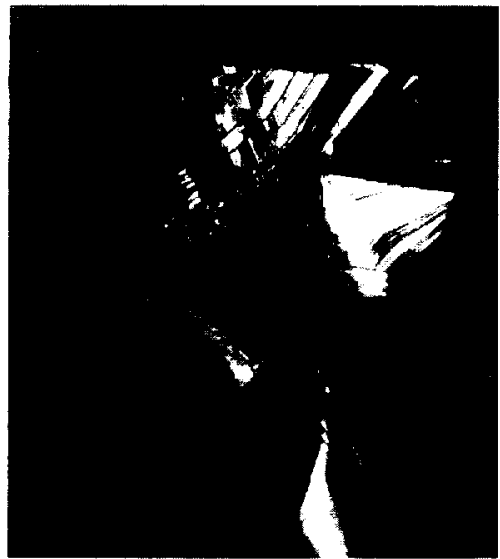

(a)

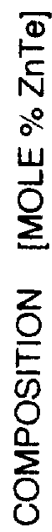

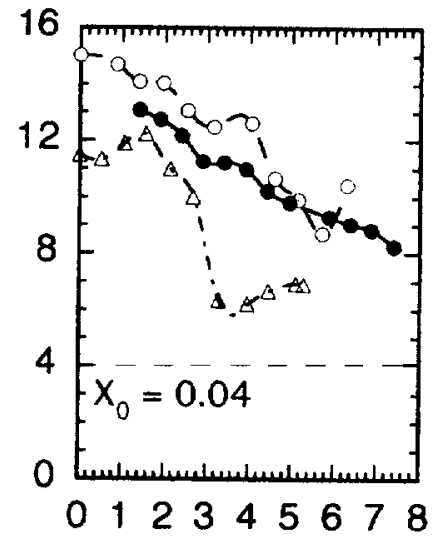

COORDINATE, $\mathrm{L} \quad[\mathrm{mm}]$

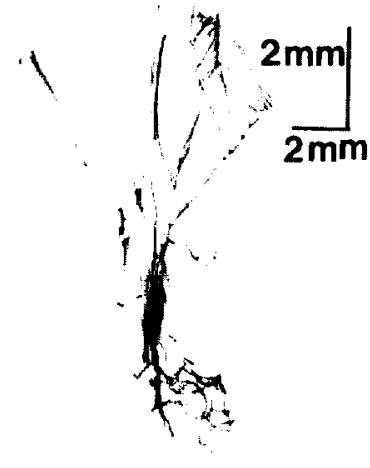

(c)

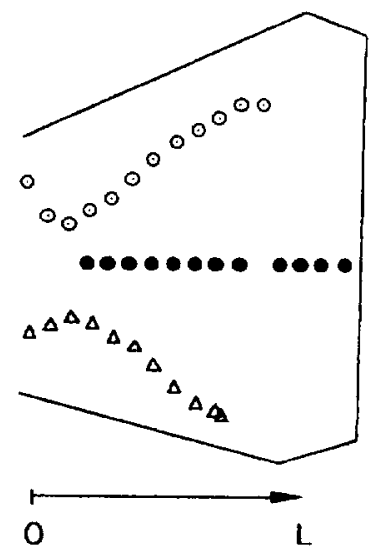

(b)

Fig. 3. Growth on the source, $x_{0}=0.04$. (a) crystal (grid in $\mathrm{mm}$ ); (b) representative composition profiles (electron microprobe analysis results. left) and scanning paths (right) across the crystal; (c), SWBX reflection topograph, $g=(\overline{4} 0 \overline{4})$.

and twinned oriented regions select different wavelengths for diffraction and give rise to images which are shifted with respect to each other depending on the particular reflection. This can be used to reveal the orientation relationships between the matrix and twinned regions. Dislocations can be identified when the distortion field around a dislocation diffracts kinematically giving rise to enhanced diffracted intensity compared with the surrounding perfect region which diffracts dynam- ically. Sub-grain boundaries comprise of dislocations usually arranged in a tilt fashion and can be identified by means of orientation contrast. The contrast of precipitates depends on the strain field associated with a precipitate. Normally a spherical precipitate has a radial strain field. Images of such precipitates consist of two dark, kinematic lobes positioned in the \pm directions of the reciprocal lattice vector (diffraction vector, $g$ ) for a given reflection (topograph), separated by a region of 
significant lattice rotation [6]. Precipitate contrast is more complex if the strain field is non-radial. Lattice strains/distortions can be discerned in the synchrotron topographs as darker, irregular lines of variable thickness and contrast.

\subsection{Non-homogeneous strains}

Two sources of non-homogeneous strains were found in the samples. Fig. $2 a$ and Fig. $2 b$ show images of our CdTe crystal at a distance of $z=1$ and $7 \mathrm{~mm}$ from the pedestal, respectively. The sample close to the pedestal (Fig. 2a) shows severe lattice distortions, which are essentially absent in the further part of the crystal (Fig. 2b). Apparently the large inhomogeneous strains were caused by sticking of the crystal to the pedestal and a resulting stress (caused by a difference in thermal expansion coefficients of fused silica and crystal) developed upon cooling the ampoule after growth.

Another source of lattice strain is illustrated in Fig. 3. The crystal (Fig. 3a) has formed on the source (without excess $\mathrm{Cd}$ ) by local resublimation and with no contact with the walls of the ampoule [4]. However, the composition of the crystal is very non-uniform (Fig. 3b) what apparently leads to severe distortions of the crystal lattice (Fig. 3c). Similar lattice distortions were observed in other crystals with non-uniform distribution of zinc in the lattice (Fig. 4a and Fig. 4b). Growth under very low undercooling or excess $\mathrm{Cd}$ pressure improves compositional homogeneity of the crystals $[7,8]$. With sufficient $\mathrm{Cd}$ pressure, high compositional uniformity and essentially elimination of the lattice distortion can be achieved (Fig. 4a and Fig. 4c).

\subsection{Precipitates}

Precipitates $(\mathrm{P})$ were observed in all crystals independent of their composition and growth conditions. The precipitates were found to be tellurium-rich $(>90 \% \mathrm{Te})$ as determined by the SEM/EDS analysis. Some were associated with an oval contrast precipitate feature (PF) around them. Relatively small (less than $100 \mu \mathrm{m}$ ) and larger (up to $800 \mu \mathrm{m}$ in diameter) features were observed in cadmium telluride (Fig. $2 b$ and Fig. 5a). Generally larger ones (up to a few $\mu \mathrm{m}$ in diameter, Fig. $4 \mathrm{~b}$,

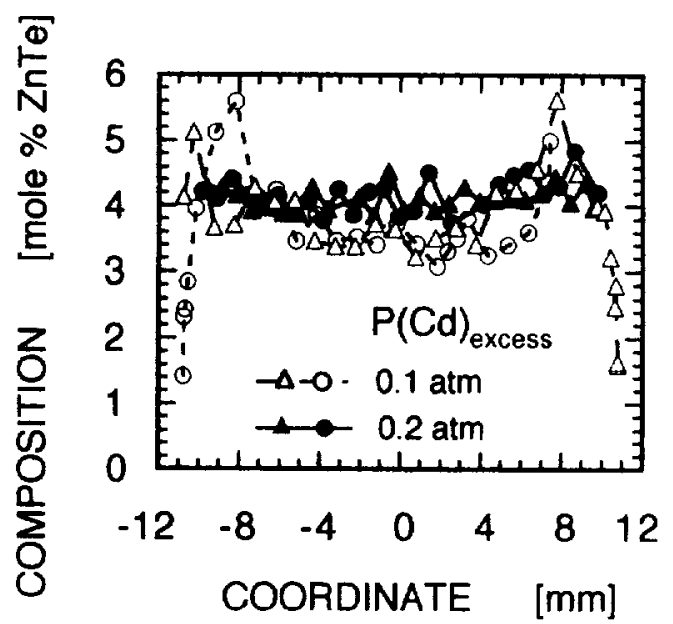

(a)

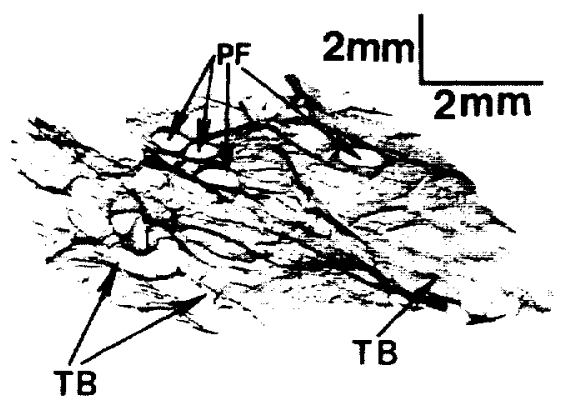

(b)

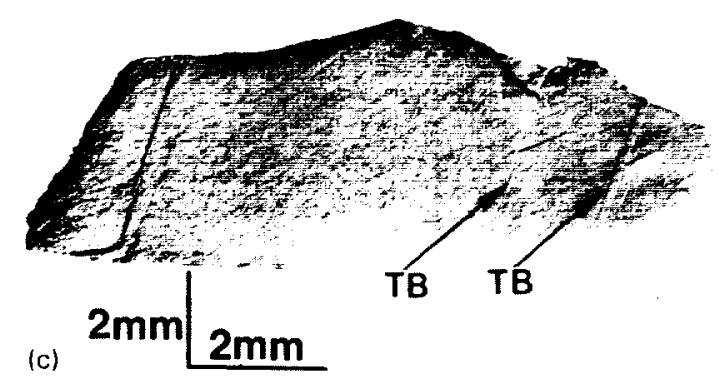

Fig. 4. Lateral composition profiles of ( $\mathrm{Cd}, \mathrm{Zn}) \mathrm{Te}$ crystals and SWBX reflection topographs of their representative samples. $x_{0}=0.04 . \mathrm{PF} \cdots$ precipitate contrast features, TB - twin boundaries. (a), lateral composition profiles; (b) $P(C d)_{\text {excess }}=0.1 \mathrm{~atm}$, reflection topograph; $(\mathrm{c}), P(\mathrm{Cd})_{\text {excess }}=0.2 \mathrm{~atm}$, reflection topograph, $\boldsymbol{g}=\left(\begin{array}{lll}5 & 3 & \overline{1}\end{array}\right)$.

Fig. 5b, Fig. 6a, Fig. 6b, and Fig. 7) were observed in cadmium-zinc telluride samples. Fig. 6a and Fig. $6 \mathrm{~b}$ show reflection (top) and transmission (bottom) images of samples of $x=0.04$ and 0.20 , 


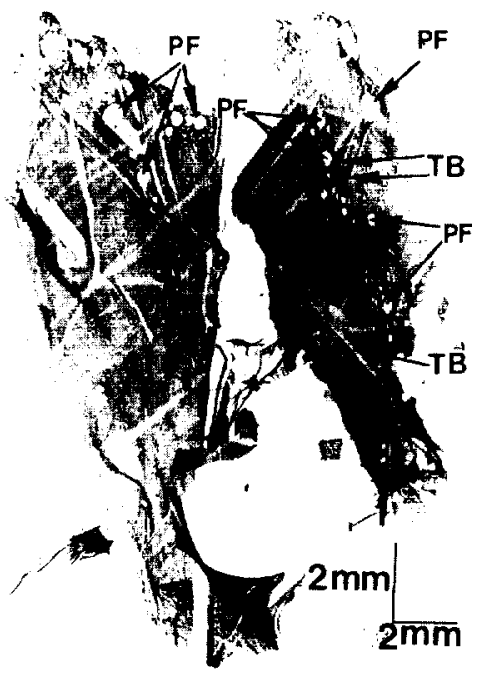

(a)

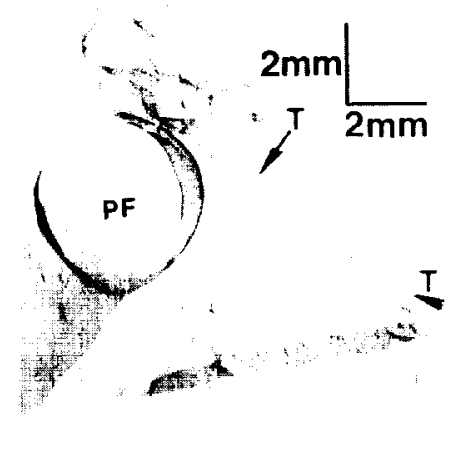

(b)

Fig. 5. SWBX reflection topographs. PF - precipitate contrast features, T - twin bands, TB - twin boundaries. (a) CdTe, $g=(53)$ ); (b) $(\mathrm{Cd} . \mathrm{Zn}) \mathrm{Te}, x_{0}=0.04, g=(\overline{3} \overline{3} \overline{5})$.

respectively. The oval contrast features in the upper figures (reflection mode) are centered in locations corresponding to Te precipitates observed in the lower micrographs (transmission mode) (Fig. 6a and Fig. 6b). The strain field is apparently caused by high density of dislocation loops formed around Te precipitates [9]. Relatively limited number of the contrast features in the samples suggests, that the long range strain field forms only around larger size precipitates. Based on our earlier studies of $(\mathrm{Cd}, \mathrm{Zn}) \mathrm{Te}$ crystals grown by PVT under similar conditions, the largest precipitates are about $1-2 \mu \mathrm{m}$ in size [3]. That means, that distortion of the lattice caused by the precipitates may be three orders of magnitude larger than the size of the precipitate alone.

In general, formation of a second phase of the constituent element in a crystal $(\mathrm{Cd}, \mathrm{Zn}$, or Te in cadmium-zinc telluride) can be due to two basic mechanisms [10]. Retrograde solubility of constituent element(s) leads to supersaturation and formation of precipitates (typical size a few nanometers) upon cooling to lower temperatures. Mechanical entrappment of non-congruent melt by the growing crystal surface leads to formation of inclusions (which may reach a few $\mu \mathrm{m}$ and more in size). Under our experimental conditions, partial pressures of $\mathrm{Zn}, \mathrm{Cd}$, and $\mathrm{Te}$ are about one order of magnitude or more below the respective saturation pressures. Therefore formation of a macroscopic (a few $\mu \mathrm{m}$ or more in thickness) liquid layer on the growing crystal surface is not possible, and has not been observed. In view of the above the tellurium features observed in our crystals seem to be precipitates formed after growth. However, the mechanism of formation of these large precipitates is not clear at this moment.

\subsection{Linear defects}

Except for the seed crystal (Fig. 3c), all larger size grains show a presence of 180 twins ( $\mathrm{T}$ - twins, TB twin boundaries, Fig. 2b, Fig. 4b, Fig. $4 c$ and Figs. 5-8). That implies, that the probability of occurrence of a twin feature increases with the increase in the size of the grain. In some samples slip bands (S) regions were observed (Fig. $2 b$ and Fig. 7). They do not cross the twin boundary lines, 

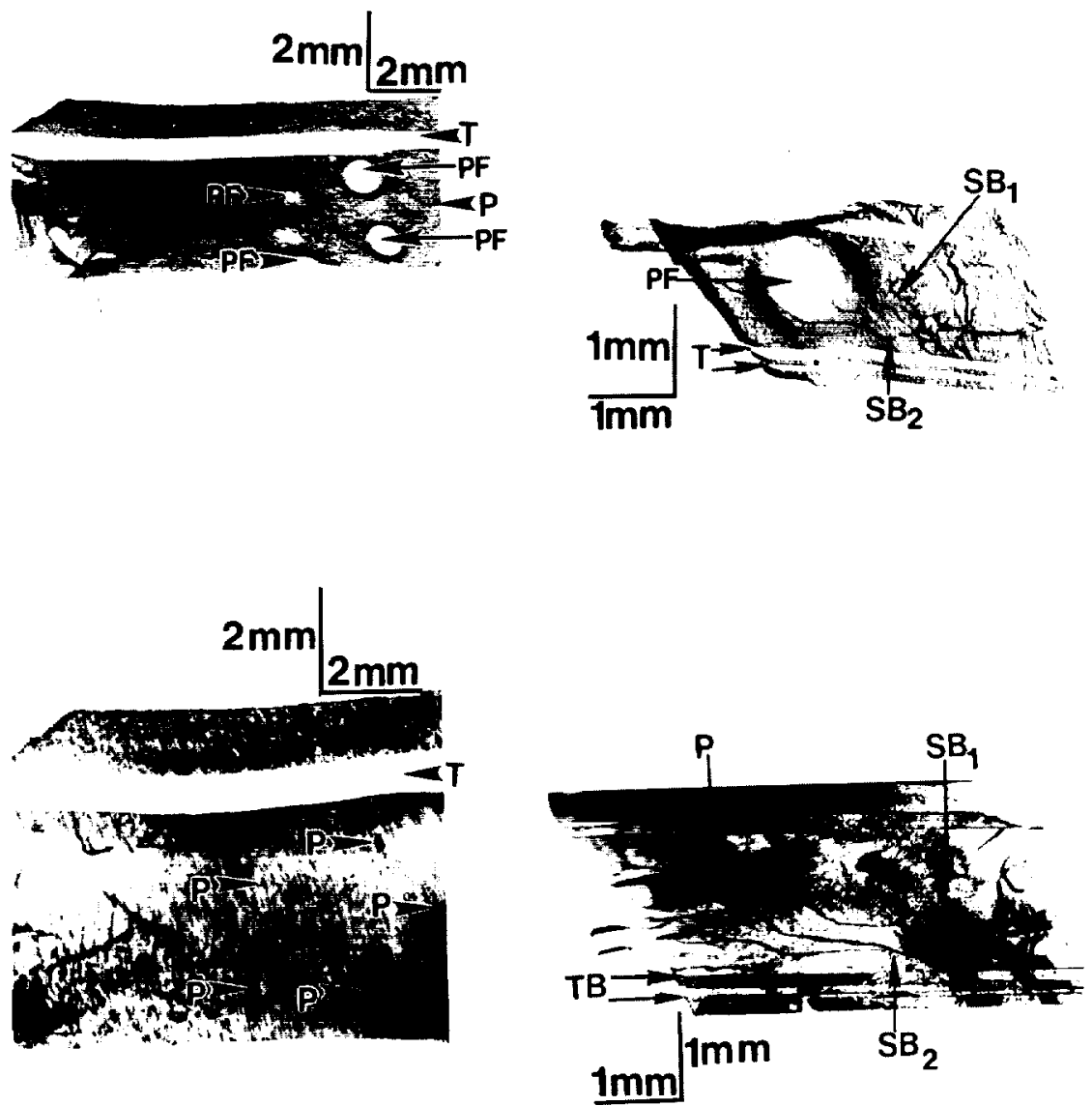

(a)

(b)

Fig. 6. SWBX topographs. $\mathrm{P}$ precipitates, $\mathrm{PF}$ precipitate contrast features, $\mathrm{T}$ - 1 win bands. TB - twin boundaries. $\mathrm{SB}_{1}, \mathrm{SB}_{2}$ subgrain boundaries. (al), $x_{0}=0.04, P(\mathrm{Cd})_{\mathrm{excess}}=0.2 \mathrm{~atm}$; (b). $x_{0}=0.2 . P(\mathrm{Cd})_{\mathrm{cxuew}}=0.1 \mathrm{~atm}$. Top reflection geometry (left,

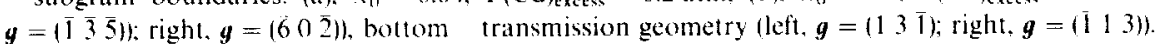

what indicates that the twinning occurred earlier than the slip process and that the twin boundaries act as a barrier to dislocation motions $[11,12]$. The above observations support earlier literature conclusions $[13,14]$, that twinning is primarily the growth phenomenon, and not the result of the crystal deformation under stress.

Two types of subgrain boundaries, probably generated by stresses (due to possible local compositional nonuniformities) were observed in crystals of high concentration of zinc $(x \geqslant 0.2)$. The first type $\left(\mathrm{SB}_{1}\right.$ in Fig. $6 \mathrm{~b}$ and Fig. 8$)$ forms cell structures comprised of an array of subgrain boundaries hav- ing the width of $50-200 \mu \mathrm{m}$ with regions of very low dislocation (D) density. The subgrains must have been formed by the mechanism of dislocation glide and climb [15]. The formation of the second type of subgrain boundaries, which are long and straight $\left(\mathrm{SB}_{2}\right.$, Fig. 6b), may arise from polygonization of slip dislocations [16]. The boundaries might have formed during growth or post-growth cooling period ( $\mathrm{T}$ (source) $\rightarrow 100 \mathrm{C}$ in $3 \mathrm{~h}$ ).

Dislocation densities of the better samples (Fig. 1b, Fig. 4c. Fig. 6a and Fig. 7) are in the low $10^{4} / \mathrm{cm}^{2}$ range what is consistent with etch pit density results reported earlier [4] 


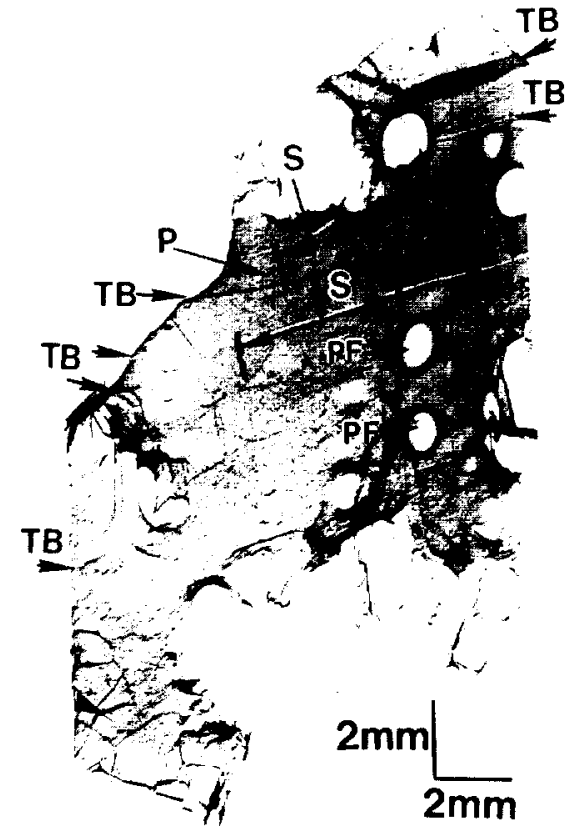

Fig. 7. SWBX rellection topograph, $y=(426) . P$ precipitates, $\mathrm{PF}$ precipitatecontrast features, $\mathrm{TB}$ twin boundaries, $S$ slip bands. $x_{0}=0.04, P(C d)_{\text {exce }}=0.2 \mathrm{~atm}$.

\section{Summary}

Cadmium telluride and cadmium-zinc telluride crystals grown by 'contactless' PVT have been characterized using synchrotron white beam X-ray topography. Large inhomogeneous strains present in some samples were found to be caused by interactions with the ampoule (sticking to the pedestal) and by composition gradients (non-uniform distribution of $\mathrm{ZnTe}$ ) in the material. A presence of an occasional oval strain field (up to a few $\mu \mathrm{m}$ in size) was observed in a number of samples. The strain fields were found to occur around (larger) Te-precipitates and to be about three orders of magnitude larger than the precipitates alone. Twin grains present in the crystals were formed during growth and not by thermal stresses caused by temperature and/or composition gradients. Low angle boundaries were formed occasionally in crystals of higher $(x \geqslant 0.2)$ concentration of zinc telluride.

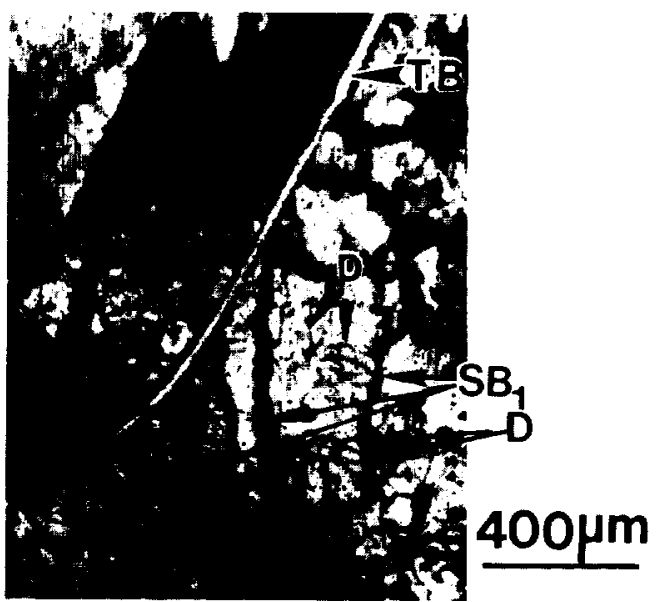

Fig. 8. Magnified transmission topograph of a region with subgrain boundaries, $g=\left(\begin{array}{l}02 \\ 2\end{array}\right)$. TB twin boundaries, $S_{B_{1}}$ subgrain boundaries. $D$ dislocations.

\section{Acknowledgements}

The support of this work by the Microgravity Science and Applications Division of the National Aeronautics and Space Administration is gratefully acknowledged. Valuable comments and suggestions by Professor Ken Durose of Durham University are greatly appreciated.

\section{References}

[1] A. Szilagyi, M.-N. Grimbergen, J. Crystal Growth 86 (1988) 912.

[2] J.F. Buttler, C.L. Lingren, F.P. Doty. IF.E. Trans. Nucl. Sci. 39 (1992) 605 .

[3] W. Paloss. M.A. Georgc, E.E. Collins. K.-T. Chen, Y. Zhang. Z. Hu, A. Burger. J. Crystal Growth 174 (1997) 733.

[4] W. Palosz, K. Grasza, D. Gillies, G. Jerman, J. Crysta] Growth $169(1996) 20$

[5] (i.-1). Yao, M. Dudley, J. Wu. J. X-ray Sci. Technol. $2(1990) 195$.

[6] B.K. Tanner, X-ray Diffraction Topography, Pergamon. New York. 1976.

[7] W. Palosz, S.L. Lehoczky, F.R. Szofran. J. Crystal Growth $148(1995) 49$.

[8] W. Palosz, F.R. Szofran, S.L. Lehoczky, J. Crystal Growth $148(1995) 56$.

[9] R.D.S. Jadava, R.K. Balgai. W.N. Borle. J. Electron. Mater. $21(1992) 1001$. 
[10] P. Rudolph, A. Engel, I. Schentke, A. Grochocki, J. Crystal Growth 147 (1995) 297.

[11] S. Tohno, A. Katsui, J. Crystal Growth 74 (1986) 362 .

[12] W. Zhou, M. Dudley, J. Wu, C.H. Su, M.P. Volz, D.G. Gillies, F.R. Szofran, S.L. Lehoczky, Mater. Sci. Eng. B 27 (1994) 143
[13] E.L. Hall, J.B. Van der Sande, Phil. Mag. 37 (1978) 137.

[14] A.W. Vere, S. Cole, D.J. Williams, J. Electron. Mater. 12 (1983) 551.

[15] S. McDevitt, B.E. Dean, D.P. Ryding, F.J. Scheltens, S Mahajan, Mater. Lett. 4 (1986) 11.

[16] K. Durose, G.J. Russell, J. Crystal Growth 86 (1988) 471 


\title{
Journal of Crystal Growth
}

\author{
Instructions to Authors (short version)
}

Submission of papers

Manuscripts (one original + two copies), should be sent to a member of the Editorial Board or preferably to an appropriate subject Associate Editor. News or announcements should be submitted through the Principal Editor; a duplicate should be sent directly to Elsevier Science B.V., address given below.

Original material. Submission of a manuscript implies it is not being simultaneously considered for publication elsewhere and that the authors have obtained the necessary authority for publication

\section{Types of contributions}

Original research papers, Letters to the Editors and Priority communications are welcome. They should contain an Abstract (of up to 200 words) and a Conclusion section, which particularly in the case of theoretical papers translates the results into terms readily accessible to most readers.

As a guideline: experimental papers should not be longer than 16 double-spaced typed pages, and 8 figures + tables; for theoretical papers a maximum of 20 pages and 10 figures + tables is suggested.

Letters and Priority communications should not be longer than 5 double-spaced typed pages, and 3 figures + tables. They will be given priority in both the refereeing and production processes. The faster production schedule may preclude sending proofs of Letters and Priority communications to authors.

\section{Manuscript preparation}

Contributions may be written in English, French or German. They should have an abstract in English. The paper copies of the text should be prepared with double line spacing and wide margins, on numbered sheets.

Structure. Please adhere to the following order of presentation: Article title, Author(s), Affiliation(s), Abstract, PACS codes and keywords, Main text, Acknowledgements, Appendices, References, Figure captions, Tables.

Corresponding author. The name, complete postal address, telephone and fax numbers and the e-mail address of the corresponding author should be given on the first page of the manuscript.

Classification codes/keywords. Please supply one to four classification codes (PACS and/or MSC) and up to six keywords of your own choice that describe the content of your article in more detail.

References. References to other work should be consecutively numbered in the text using square brackets and listed by number in the Reference list. Please refer to the more detailed instructions for examples.

\section{Illustrations}

Illustrations should also be submitted in triplicate: one master set and two sets of copies. The line drawings in the master set should be original laser printer or plotter output or drawn in black india ink, with careful lettering, large enough $(35 \mathrm{~mm})$ to remain legible after reduction for printing. The photographs should be originals, with somewhat more contrast than is required in the printed version. They should be unmounted unless part of a composite figure. Any scale markers should be inserted on the photograph itself, not drawn below it.
Colour plates. Figures may be published in colour, if this is judged essential by the Editor. The Publisher and the author will each bear part of the extra costs involved. Further information is available from the Publisher.

\begin{abstract}
After acceptance
Important. When page proofs of the accepted manuscripts are made and sent out to authors, this is in order to check that no undetected errors have arisen in the typesetting (or file conversion) process. At the proof stage only printer's errors may be corrected. No changes in, or additions to, the edited manuscript will be accepted.

Notification. The authors will receive the final answer of acceptance or rejection from the Office of the Principal Editor and will be invited to supply an electronic version of the accepted text, if this is not already available.

Copyright transfer. In the course of the production process you will be asked to transfer the copyright of the article to the Publisher. This transfer will ensure the widest possible dissemination of information.
\end{abstract}

\section{Electronic manuscripts}

The Publisher welcomes the receipt of an electronic version of your accepted manuscript. If there is not already a copy of this (on diskette) with the journal editor at the time the manuscript is being refereed, you will be asked to send a file with the text of the accepted manuscript directly to the Publisher by e-mail or on diskette (allowed formats 3.5" or 5.25" MS-DOS, or 3.5" Macintosh) to the address given below. (When e-mailing a non-ASCII word-processor file, you should encode it, e.g. with UUENCODE or BinHex, so as to retain all formatting codes.) The name and version of the word-processing program and the type of operat. ing system should always be indicated. Please note that no deviations from the version accepted by the Editor of the journal are permissible without the prior and explicit approval by the Editor. Such changes should be clearly indicated on an accompanying printout of the file.

\section{Author benefits}

No page charges. Publishing in Journal of Crystal Growth is free.

Free offprints. The corresponding author will receive 50 offprints free of charge. An offprint order form will be supplied by the Publisher for ordering any additional paid offprints.

Discount. Contributors to Elsevier Science journals are entitled to a $30 \%$ discount on all Elsevier Science books.

\section{Further information (after acceptance)}

Elsevier Science B.V., J. Crystal Growth
Issue Management Physics
and Materials Science
P.O. Box 2759, 1000 CT Amsterdam
The Netherlands
Fax: $+31204852319 /+31204852704$
E-mail: matsci-de-f(a)elsevier.nl


